\title{
Micromole Per Liter Per Second
}

National Cancer Institute

\section{Source}

National Cancer Institute. Micromole Per Liter Per Second. NCI Thesaurus. Code C105498.

A concentration unit equal to one micromole of solute in one liter of solution per unit of time equal to one second. 